\title{
它运只A
}

Article

\section{A community-based exercise program for ambulant adolescents with cerebral palsy, a feasibility study}

Asfarina Zanudin ${ }^{1,2^{*}}$, Thomas H Mercer², Cynthia Samaan², Kavi C Jagadamma ${ }^{2}$, Gillian McKelvie $^{3}$, Marietta L van der Linden ${ }^{2}$

Received: 22 ${ }^{\text {nd }}$ November 2019; Accepted: $21^{\text {st }}$ March 2021; Published: $15^{\text {th }}$ November 2021

Abstract: The aim of this study was to investigate the feasibility of an 18-week exercise program for adolescents with cerebral palsy (CP). Fourteen individuals aged 16-25 (GMFCS I-III) performed aerobic and strength exercises at their community leisure centre up to three times a week. A physiotherapist provided instruction at the first session and between 2-4 times thereafter. The fitness instructor on duty provided supervision when required. Feasibility of the exercise program was explored through an exercise logbook and participant feedback questionnaire. Gross motor function, muscle strength, aerobic capacity and the Timed Up and Go test were assessed at baseline, 6, 12 and 18 weeks. Quality of life and self-esteem were measured at baseline, 12 and 18 weeks. Participants completed a mean 14.8 (range 5-23) weeks of the exercise program and a mean of 31 (range 10-52) sessions. The results of the feedback questionnaire suggested that the exercise program was mostly well accepted. Adverse effects (muscle soreness and fatigue) were reported by three participants. Results indicated the feasibility of a community exercise program for adolescents with $\mathrm{CP}$ and recommendations for sustainable exercise programs for this group were provided.

Keywords: Physical Function, Gross Motor, Mental Health, Quality of Life, intervention

\section{Introduction}

Pediatric care for people with CP is generally quite comprehensive and involves regular multidisciplinary treatment such as orthopedic surgery (Kiapekos, Broström, Hägglund \& Åstrand, 2019) and physiotherapy (Lauruschkus et al., 2013; Majnemer et al., 2014). However, once the young person reaches a certain age, generally around 16-21 years, they are discharged from child services (Blackman \& Conaway, 2014). There is evidence suggesting that transition arrangements between child and adult services often lack coordination and that suitable adult services are not always available (Blackway \& Conway, 2014). Liljenquist and colleagues (2018) reported a clear decrease in frequency of physiotherapy services once adolescents with $\mathrm{CP}$ leave secondary school whereas Majnemer et al. (2014) concluded that adolescents were less likely to receive rehabilitation services compared to children. This is a concern with regard to the decrease in walking ability (Bottos, Feliciangeli, Sciuto, Gericke \& Vianello, 2015; Opheim, McGinley, Olsson, Stanghelle, \& Jahnsen, 2013) and high prevalence of secondary conditions such as pain and joint deformities in adults with CP (Benner et al., 2017). Regular participation in exercise may help to prevent or manage secondary conditions and maintain functional mobility in 
adulthood (Rimmer, Chen, \& Hsieh, 2011). With a view to the reduced access to health care services, such exercise programs will need to be accessible in the community in order to be sustainable. However, it has been suggested that exercise programs may still need to include the input of a health care professional depending on the needs of the person with a disability (Rimmer, Riley, Wang, Rauworth, \& Jurkoswski 2004).

A recent Cochrane review (Ryan, Cassidy, Noorduyn, \& O’Connell, 2017) highlighted a lack of exercise studies involving adults with CP (>20 years old). In addition, Lai et al. (2020) recommended that future studies should identify strategies that promote both long-term and sustainable physical participation. However, studies reporting on the feasibility of sustainable community-based exercise interventions for adolescents with CP are rare. Only Shields and colleagues (2019) reported on a range of feasibility aspects of a community exercise program for youth with disabilities (mean age of 18 years), in which only 7 of the 19 people who participated were diagnosed with CP.

The exercise program developed for this feasibility study was based on a youth exercise referral program already in place in the community for those aged 11-18 years old. The program required participants to exercise at their local leisure centre after instruction by a physiotherapist during their first session and with a maximum of a further four sessions for the remainder of the 18 weeks program. Based on current evidence (Ryan et al., 2017) the program consisted of both resistive and aerobic training components and was hypothesized to improve aspects of physical health (e.g. muscle strength, aerobic fitness and physical health related quality of life), psychosocial outcomes (e.g. self-esteem) and mental health related quality of life.

High self-esteem can lead to positive qualities such as life satisfaction, positive social adjustment, independence, adaptability and resilience to stress (Biddle, Fox, \& Boutcher, 2003) and has therefore emerged as a strong predictor of mental well-being and quality of life (Diener, 1994). However, only a few studies have included psychosocial outcomes such as self-esteem in adolescents with CP (e.g. Slaman et al., 2015a).

Feasibility studies are conducted to determine whether a certain intervention is appropriate for further testing. Bowen et al. (2009) proposed a range of key areas to be addressed in feasibility studies which include the 'acceptability' and 'practicality' of the intervention and 'limited efficacy testing' ('does a new program show promise in being successful?'). In a more recent publication focused specifically on feasibility studies in exercise and physical activity research, El-Kotob and Giangregorio (2018) listed 'adherence to the program', 'acceptance' and 'adverse events', 'recruitment rate' and 'consent rate' as feasibility outcomes.

Feasibility outcomes such as recruitment rate and the rate of outcome measure completion are often more related to the ability to conduct the study (e.g. trial design) than the exercise intervention itself. We have thus regarded the feasibility of conducting the trial as a separate feasibility outcome. The aims of this study were therefore to a) examine the feasibility of a community-based exercise program for ambulant adolescents with $\mathrm{CP}$, and b) examine the feasibility of conducting a study aimed at investigating the effectiveness of such an exercise program.

\section{Materials and Methods}

\section{Study design}

This feasibility study was a pre-post quantitative design. According to the first aim, feasibility of the exercise program was assessed through recording of adherence to the prescribed exercise frequency and duration of the 18-week program, fidelity (type of exercise, duration and intensity of the exercise, progression), acceptance of the exercise program and adverse effects. With regard to our second aim, the feasibility of conducting 
the trial was explored through the recording of recruitment rate and rate of outcome measures completion. The assessment of outcomes of physical health (muscle strength, gross motor function and aerobic fitness) took place at baseline prior to the intervention period (To), at approximately 6 weeks (T1), 12 weeks (T2) and at 18 weeks (T3) after the start of intervention period. Although exercise intervention studies have shown improvements in physical fitness such as muscle strength as early as 6 weeks (e.g. Dodd, Taylor, \& Graham, 2003), measures related to quality of life have been only observed in exercise interventions lasting 12 weeks or more (e.g. Verschuren et al., 2007; Slaman et al., 2015a). For this reason and to minimise assessment burden, physical and mental healthrelated quality of life and self-esteem were only assessed at To, T2 and T3.

\section{Participants}

Individuals with CP between 16 and 25 years of age, discharged from paediatric service or receiving physiotherapy input less than once a month and able to ambulate with or without aids (Gross Motor Functional Classification System [GMFCS] I-III; Palisano et al., 1997) were eligible for inclusion in this study. Individuals currently participating in a regular gym-based exercise training program, with insufficient cognitive ability to give informed consent, or to understand and provide answers to questions in the questionnaire booklet were excluded from participation. Other exclusion criteria were medical contraindications to participating in an exercise program and orthopaedic surgery or Botulinum Toxin type A injection in the last 6 months.

Four hundred and thirty-one potential participants were identified from client lists of the local Gait Analysis Laboratory and local community physiotherapists and were sent a letter inviting them to participate in this study. Twenty-one young people returned a form expressing an interest in taking part. Sixteen gave consent and underwent baseline assessment of which 14 started the exercise program. The participant flow is shown in Figure 1.

Characteristics of the 14 participants who took part in the exercise program are included in Table 1. All participants signed an informed consent form prior to taking part and the study was approved by the Lothian National Health Services (NHS) research ethics committee (11/AL/o044) and the Queen Margaret University research ethics committee.

Table 1. Characteristics of the participants who started the study $(n=14)$.

\begin{tabular}{|c|c|c|c|}
\hline & Frequency & Means & $\mathrm{SD}$ \\
\hline Gender (male/female) & $8 / 6$ & & \\
\hline Age (years) [range] & & 19.3 [16-24] & 3.1 \\
\hline GMFCS (I/II/III) & $4 / 6 / 4$ & & \\
\hline spastic hemiplegia/spastic diplegia/ataxia & $4 / 9 / 1$ & & \\
\hline Height (m) & & 1.63 & 0.1 \\
\hline Body mass (kg) & & 62 & 19 \\
\hline BMI (kg/m2) & & 23.2 & 6.2 \\
\hline $\begin{array}{l}\text { Assistive devices during } \\
\text { (Sticks/crutches/walker/wheelchair/none) }\end{array}$ & & & \\
\hline Timed Up and Go test & $1 / 1 / 2 / 0 / 10$ & & \\
\hline Other indoor & $1 / 2 / 3 / 1 / 7$ & & \\
\hline Community distances & $0 / 0 / 0 / 8 / 6$ & & \\
\hline Physically active at baseline (yes/no) & $13 / 1$ & & \\
\hline
\end{tabular}




\section{Intervention}

The protocol required participants to exercise at their local leisure centre three times per week for weeks 1-6 (Block 1) and twice a week but encouraged to attend three times a week for weeks 7-12 (Block 2). There was no prescribed number of exercise sessions for weeks 13-18 (Block 3) in order to assess the participants' preferred (and thus likely to be sustainable) exercise frequency.

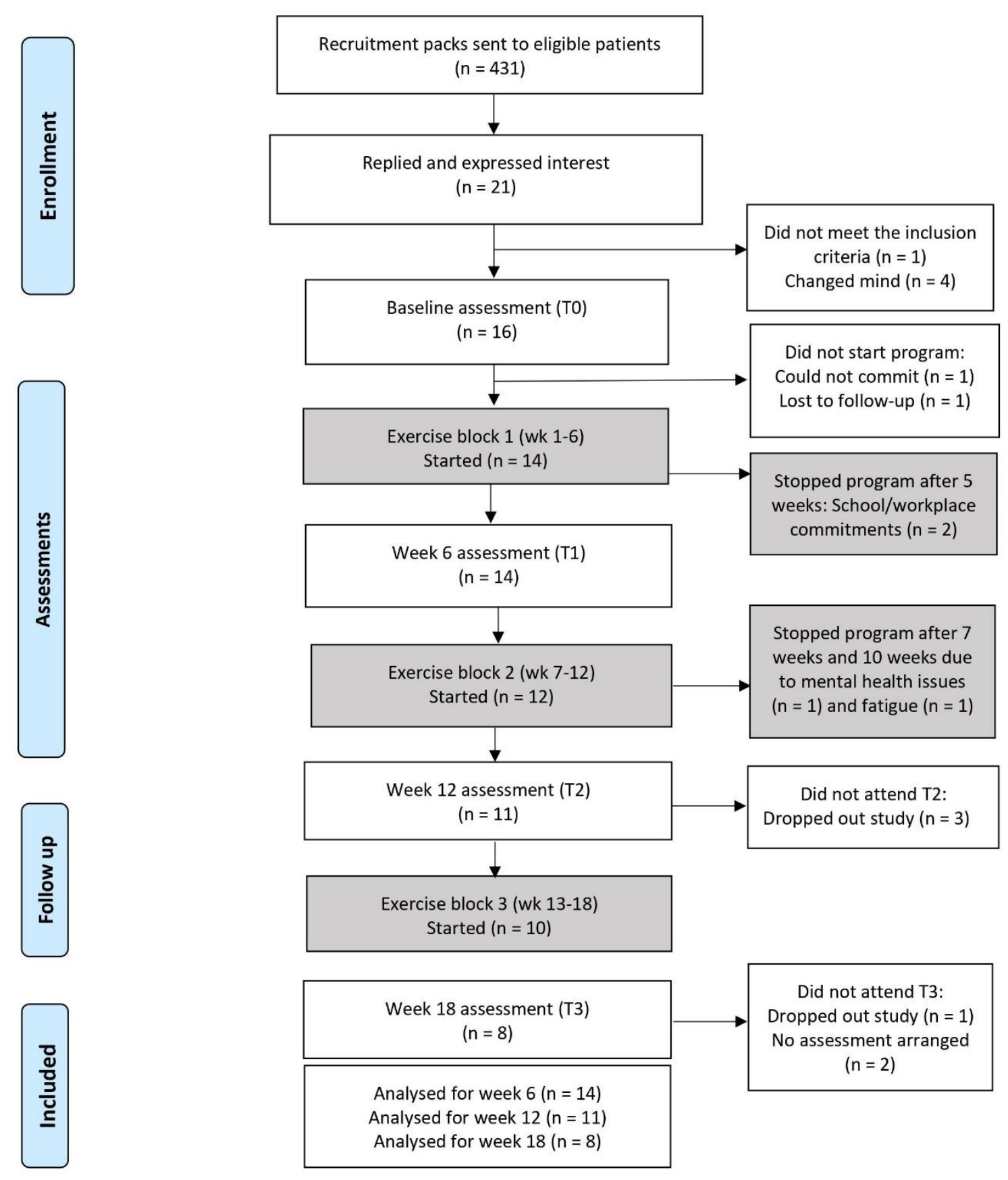

Figure 1. Flowchart of the participants in the study for both the participation in the exercise program (shaded boxes) and in the study assessments (white boxes).

Participants undertook individual circuit exercise training sessions, comprising of strength training and aerobic exercise, at their local leisure centre. For the first session and a further two to four sessions during the first 12 weeks of the exercise program, a paediatric physiotherapist, experienced with exercise referrals to leisure centres, instructed the participants with regard to the exercises. This was to ensure these were adopted to the ability 
of the participant and were at the appropriate level. A fitness instructor also attended these sessions with the physiotherapist. This allowed them to instruct or assist the participants for any exercise sessions throughout the 18-week exercise program when this was required. Participants were provided free access to the leisure centre fitness facilities for the duration of the exercise program.

\section{Exercise program content}

Each visit to the leisure centre was broken into three 5-minute bouts of aerobic exercise interspaced with two segments of four different strength training exercises ( 8 in total) focusing on knee extensors, hip extensors, hip abductors, dorsiflexors and core stability (Figure 2). For the aerobic segments, participants used either a reclining exercise bike or treadmill. One participant used an exercise bike with motorized assistance (MOTOmed). Participants were asked to exercise at a perceived level of exertion of 13 ('somewhat hard') on the 6-20 Borg Scale (Borg, 1998). Strength exercises were performed either with standard fitness equipment such as weights machines, TheraBands, Swiss balls (core stability exercises) or without equipment such as walking on heels, single leg raises and hip extension against gravity. The strength exercises were adapted to the level of ability of the participants. For example, those unable to use the exercise machines used their own body weight or Therabands for resistance.

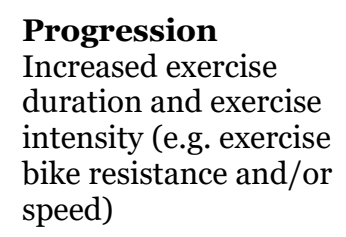

Progression

Increased exercise intensity (e.g. exercise speed)
Initial programme

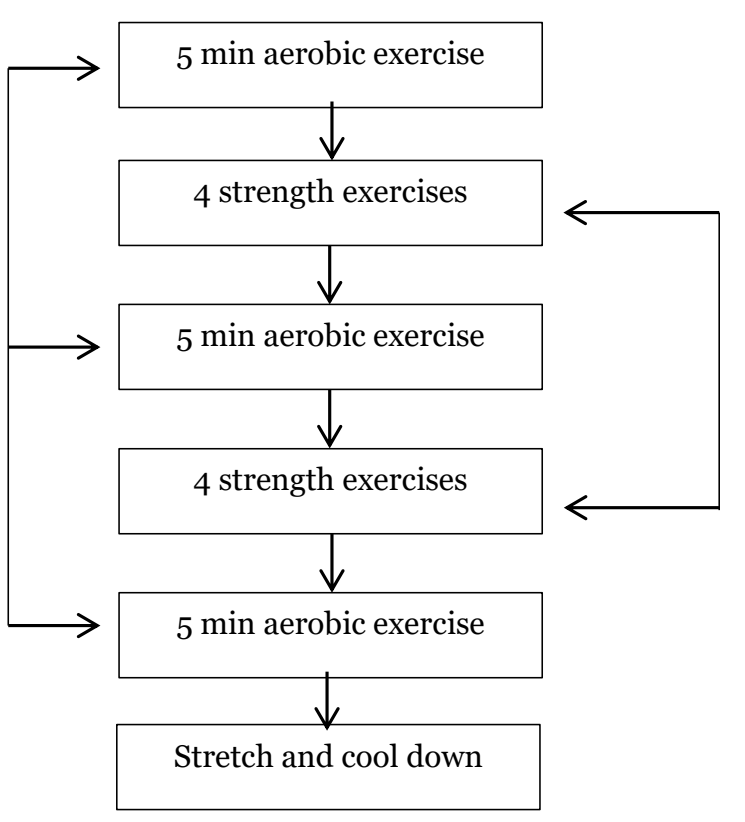

\section{Progression:}

Every 2 weeks, if 12 reps can be comfortably achieved, increase resistance

Figure 2. Exercise content. The 8 strengthening exercises were: Leg press (or leg extensions), plantarflexor strengthening (TheraBands or toe raises), trunk rotation ball twist while seated on Swiss ball), single leg stand or dip, hip extensor strength (standing or in kneeling), dorsiflexor strength (walking on heels, seated dorsiflexion), squats, hip abductor strength (standing or side lying).

In the first week of the program, participants were asked to do one set of 10 repetitions for each of the strength exercises performed at the predetermined 10-repetition maximum (10RM). The 1ORM is the heaviest weight that participant can perform for 10 repetition while maintaining a good form (American College of Sports Medicine, 2013). At week 5 of the program an individual component was included. For this component, the physiotherapist identified individual weaknesses and selected four out of the eight exercises for which participants were to complete two sets instead of only one. The structure of the program remained the same. 


\section{Progression}

Throughout the program, every two weeks participants were asked to perform a 'selfassessment'. This assessment determined whether to increase the resistance for a particular exercise. For each exercise, participants attempted to complete 12 reps on their last (or only) set. If 12 reps could be achieved comfortably, the resistance for that exercise was increased incrementally during the following training session. For the weight machines and exercises where free weights were used as resistance, this was done by increasing the weight by the smallest increment possible. In cases where TheraBands provided resistance, the TheraBand was doubled, or a band with a greater resistance was used. Progression of aerobic component was by increasing either the duration or the level of resistance in case of the exercise bikes or walking speed for the treadmill, as long as the perceived exertion stayed at 'somewhat hard' on the 6-20 Borg Scale (Borg, 1998).

\section{Exercise logbook}

All participants were provided with an exercise log book which also included a description and illustration of the exercises and the progression of the program. Completed exercise sessions, including the exercise duration and intensity e.g. the resistance level (on the exercise bike) or speed (treadmill) and number of repetitions and level of resistance of the strength exercises were recorded in the exercise log book and signed by the attending fitness instructor. Adverse events such as muscle soreness and fatigue were also noted in the logbook.

\section{Feasibility of the exercise program and feasibility of conducting the trial}

Feasibility of the exercise program was assessed through recording of adherence (number of exercise sessions completed and drop-out from the exercise program) in the exercise logbooks. Fidelity aspects (the type of exercises performed, duration and intensity of the exercise and exercise progression) and adverse events were also retrieved from the exercise logbooks. Acceptance of the exercise program and adverse events were explored through a feedback questionnaire provided to the participants at the end of their participation in the exercise program. This questionnaire was constructed by the researchers to explore participants' views regarding the exercise program and included 15 items covering feasibility and sustainability related aspects such as acceptability of the program, perceived health benefits, adverse effects and intention to continue with exercise training or start other physical activities (Appendix I). Feasibility of conducting the trial was assessed through recording of the recruitment rate, the number of study assessments attended and the rate of outcome measure completion.

\section{Outcome measures}

Gross motor function, walking performance, isometric muscle strength, and aerobic capacity were assessed at baseline (To), week 6 (T1) and week 12 (T2), and week 18 (T3). Outcome measures were collected by either CS or AZ with the same researcher performing all assessments for each individual participant.

Gross motor function was measured using the Gross Motor Function Measure (GMFM66) dimensions $\mathrm{D}$ (standing) and $\mathrm{E}$ (walking, running and jumping) as described in the user's manual (Russell, Rosenbaum, Wright \& Avery, 2002). Walking performance and balance was measured through the Timed Up Go test (TUG). Isometric muscle strength of the hip extensors, hip abductors and knee extensors were measured in a gravity neutral position using the MIE Myometer (MIE ltd, Leeds, UK), according to Seniorou and colleagues (2002). Three trials were carried out for each muscle group and participants were given a 30-second rest between trials. The highest of the three trials was selected for 
analysis. Force values were multiplied by the lever arm to derive the moments, and these were normalized by dividing by body mass $(\mathrm{kg})$. The shuttle run/walk test was used as a measure of aerobic fitness with different protocols for GMFCS levels I, II and III (Verschuren, Takken, Ketelaar, Gorter, \& Helders, 2006). Each study visit lasted between 60-90 minutes. Measures of quality of life and self-esteem were assessed at baseline To, T2 and $\mathrm{T}_{3}$ of the exercise program. Quality of life was assessed using the Short Form12 (SF12v2), which consists of 12 questions and provides a physical and mental component score. The SF-12v2 has been found to be valid and reliable in the general population (Ware Jr, Kosinski, \& Keller, 1996) and has been used in previous studies with people with CP (e.g. Bonnefoy-Mazure et al., 2020). The Rosenberg Self-Esteem Scale (RSES) was selected to assess self-esteem and consists of 10 statements with which participants can strongly disagree, disagree, agree or strongly agree. The total score ranges between 0 and 30 with a higher value indicating a higher self-esteem. RSES has adequate validity and reliability in healthy young adults (McMullen \& Resnick, 2013) and has been used in previous studies investigating the self-esteem in people with CP (Espín-Tello, Dickinson, Bueno-Lozano, Jiménez-Bernadó, \& Caballero-Navarro, 2018).

\section{Data analysis}

Feasibility outcomes with regard to the exercise program (aim 1) and feasibility of conducting the trial (aim 2) were analysed as follows. Adherence to the prescribed number of exercise sessions and duration of exercise program, outcome completion rate and recruitment rate were summarised using descriptive statistics (means, measures of frequency). Non-numerical data such as fidelity (log books), adverse events (log books and feedback questionnaire) and acceptance of the program (feedback questionnaire) were described using frequency measures (counts, percentages).

\section{Results}

\section{Feasibility of the exercise program (Aim 1)}

The shaded boxes in Figure 1 show the participant flow with regard to the exercise program.

Exercise session attendance was recorded in the exercise logbook for all three exercise blocks of the exercise program. All participants who started the exercise programe returned their logbook except for one participant who dropped out during Block 2, hence the compliance data for 13 logbooks was available for analysis. Overall compliance in Block 1 was $81 \%$, (191 out of a possible 234 sessions, three times a week for thirteen participants). In Block 1, eight participants completed between 15-18 sessions over the first 6 weeks (i.e. mostly three times a week), and the remaining five completed 10-14 sessions (mostly twice a week). Exercise session frequency dropped in Block 2 (two prescribed sessions a week) with five participants doing between 15-18 session a week and six doing less than 10 sessions, which equated to one or two sessions per week or none. In Block 3 with no prescribed exercise frequency, two participants completed 15-18 sessions, three completed 10-14 sessions and six completed less than 10 sessions.

With regard to fidelity, the entries in the logbooks showed that all participants who had returned their logbooks $(n=13)$ were able to carry out their individually tailored exercises. One participant (GMFCS III) was not able to use any of the usual aerobic equipment (bike, rower or treadmill) and used a motorized exercise bike (MOTOmed) instead. However, the participant's local leisure centre did not have a MOTOmed which meant this participant had to travel further to another leisure centre. One participant removed the leg press from his exercise routine as it resulted in sore hamstrings. Information on progression of the strength and aerobic exercises was only available in 9 of the 13 logbooks. In all these 9 logbooks 
there was evidence that throughout the exercise program participants increased the number of sets and level of resistance for the strength exercises and duration and intensity of the aerobic exercise segments.

\section{Acceptability}

A summary of the results of the questionnaire is shown in Table 2. The results showed that all participants who returned the questionnaire (11 out of 14 who started the program) thought the length of the session (one hour) was just right. Opinions on the content of the program varied. Five thought the program was sometimes too easy, while three found it too hard at times. Six liked how the sessions were altered as they became more used to the exercises. All participants who returned the questionnaire expressed the intention to continue with the exercise program in some form with several remarking that they would like to change the content of the program $(n=2)$ or reduce the exercise frequency to once or twice a week $(n=4)$. None intended to start a new physical activity. All participants reported that the exercise program resulted in some positive effects such as being less breathless, being able to walk further, loss of weight, improved ability to transfer and feeling stronger and fitter.

Table 2. Summary of the results of the exercise program feedback questionnaire $(n=11)$.

\begin{tabular}{|c|c|c|}
\hline Questions & Answers & $\mathrm{N}$ \\
\hline \multirow[t]{3}{*}{ Level of difficulty of exercises } & About right & 3 \\
\hline & Sometimes too difficult & $3(2)$ \\
\hline & sometimes too easy & 5 \\
\hline \multirow[t]{3}{*}{ Preference of exercise } & Group & $5(1)$ \\
\hline & Alone & $4(1)$ \\
\hline & No preference & 2 \\
\hline \multirow[t]{3}{*}{ Duration of the sessions } & Just right & $11(2)$ \\
\hline & Too long & 0 \\
\hline & Too short & 0 \\
\hline \multirow[t]{2}{*}{ Variety of the exercises } & Good variety & $9(2)$ \\
\hline & Not enough variety & 2 \\
\hline \multirow[t]{3}{*}{ Individual alterations to the program } & $\begin{array}{l}\text { I liked the fact that there were no main } \\
\text { alterations }\end{array}$ & 4 \\
\hline & $\begin{array}{l}\text { I liked how the sessions were altered as I got } \\
\text { more used to the exercises }\end{array}$ & $6(1)$ \\
\hline & Not answered & $1(1)$ \\
\hline \multirow[t]{3}{*}{ Level of supervision/instruction } & Just right & $9(2)$ \\
\hline & Not enough supervision initially but fine later on & 1 \\
\hline & Not enough, instructors hardly in the gym & 1 \\
\hline $\begin{array}{l}\text { Did you note any benefits? And if so } \\
\text { which? }\end{array}$ & Yes/No & $10 / 1(1 / 1)$ \\
\hline Transfer ability & "Transferring easier" & 1 \\
\hline Muscle strength & "stronger" & 1 \\
\hline Flexibility & "Looser muscles, increased ROM" & 1 \\
\hline Weight loss & "Lost weight" & 2 \\
\hline Balance & $\begin{array}{l}\text { "maybe balance and core stability" } \\
\text { "bit steadier in exercises" }\end{array}$ & 2 \\
\hline Fitness & $\begin{array}{l}\text { "Less breathless" } \\
\text { "increased stamina" } \\
\text { "able to walk further" } \\
\text { "not as tired" } \\
\text { "fitter" }\end{array}$ & 5 \\
\hline
\end{tabular}

The responses of the two participants who dropped out the exercise program are in brackets. Free text responses are in quotes. 


\section{Adverse effects}

Two participants reported muscle soreness and one removed the leg press exercise due to sore and tight hamstrings. Four other participants reported initial muscle soreness but this disappeared as they got used to the exercise program. One participant commented in the logbook on tiredness after nearly all sessions from week two but nevertheless attended $100 \%$ of the prescribed exercise sessions for Block 1 (week 1-6) and two weeks of three weekly sessions in Block 2 but then stopped after week 8 with a diagnosis of Chronic Fatigue Syndrome.

\section{Feasibility of conducting the study (Aim 2)}

Recruitment rate was low, with only 21 of the 431 invited to the study expressing an interest and only 16 giving consent and attending for baseline assessment (4\%). The clear boxes in Figure 1 shows the participant flow with regard to the study assessments. All 14 participants who started the exercise program attended the 6 week assessment. However, three participants did not attend for the assessment at 12 weeks ( $\mathrm{n}=11$ available for analysis at T2) and a further three did not attend at the 18 week assessment ( $n=8$ available for analysis at $\mathrm{T}_{3}$ ). With regard to outcome completion rate, one participant (GMFCS III) was not able to do the shuttle walk/run test. One other participant complained of back pain during the hip exensor and hip abductor strength assessment and thus these were not recorded for this participant. One participant did not return the logbook and three did not return the feedback questionnaire. All other outcome measures were successfully recorded for all participants (Table 3).

Table 3 Outcome measure completion rate (number of outcome measures completed/ number of participants attending for the assessment) and values (Mean and SD) at each assessment point.

\begin{tabular}{|c|c|c|c|c|c|c|c|c|c|c|c|c|}
\hline & \multicolumn{4}{|c|}{$\begin{array}{l}\text { Outcome measure } \\
\text { completion rate }\end{array}$} & \multicolumn{8}{|c|}{ Means (SD) of those attending all four assessments ( $\mathrm{n}=8$ ) } \\
\hline & T0 & $\mathrm{T} 1$ & $\mathrm{~T} 2$ & T3 & & T0 & & T1 & & $\overline{T 2}$ & & T3 \\
\hline GMFM $(0-100)$ & $14 / 14$ & $14 / 14$ & $11 / 11$ & $8 / 8$ & 70 & $(15)$ & 72 & (16) & 72 & $(16)$ & 72 & (16) \\
\hline TUG (s) & $14 / 14$ & $14 / 14$ & $11 / 11$ & $8 / 8$ & 16.2 & (10.8) & 14.7 & (10.7) & 13.7 & $(9.2)$ & 14.5 & $(1$ \\
\hline Knee extensor $(\mathrm{Nm} / \mathrm{kg})$ & $14 / 14$ & $14 / 14$ & $11 / 11$ & $8 / 8$ & 1.05 & $(0.49)$ & 1.17 & $(0.52)$ & 1.23 & $(0.57)$ & 1.25 & $(0.52)$ \\
\hline$(\mathrm{Nm} / \mathrm{kg})$ & $13 / 14$ & $13 / 14$ & $11 / 11$ & $8 / 8$ & 1.08 & $(0.52)$ & 1.08 & $(0.60)$ & 1.41 & $(0.72)$ & 1.53 & $(0.61)$ \\
\hline Hip abductor $(\mathrm{Nm} / \mathrm{kg})$ & $13 / 14$ & $13 / 14$ & $11 / 11$ & $8 / 8$ & 0.67 & $(0.27)$ & 0.69 & $(0.25)$ & 0.73 & $(0.24)$ & 0.76 & $(0.24)$ \\
\hline SRT & $13 / 14$ & $13 / 14$ & $11 / 11$ & $8 / 8$ & 10.0 & (6.4) & 10.4 & $(6.6)$ & 9.7 & $(6.3)$ & 10.3 & (7.0) \\
\hline SF-12 PCS & $14 / 14$ & NR & $11 / 11$ & $8 / 8$ & 46.9 & $(9.5)$ & & NR & 46.9 & $(11.0)$ & 44.1 & (6.9) \\
\hline SF-12 MCS & $14 / 14$ & NR & $11 / 11$ & $8 / 8$ & 44.8 & $(7.2)$ & & NR & 53.2 & $(14.1)$ & 48.8 & $(13.1)$ \\
\hline RSES & $14 / 14$ & NR & $11 / 11$ & $8 / 8$ & 18.7 & $(6.5)$ & & NR & 21.2 & (6.6) & 18.8 & $(8.3)$ \\
\hline
\end{tabular}

GMFM: Gross Motor Function Measure; TUG: Timed Up and Go test; SRT: Shuttle Run Test (number of shuttles); PCS: Physical Component Score, MCS: Mental Component Score; RSES: Rosenberg Self Esteem Scale (0-30); NR: not recorded.

\section{Discussion}

The aims of the current study were to evaluate a) the feasibility of community-based exercise program for ambulant adolescents with $\mathrm{CP}, \mathrm{b}$ ) the feasibility of conducting a trial investigating the effectiveness of such an exercise program.

\section{Feasibility of the exercise program}

We found that the drop-out rate was relatively high, with only 12 of the 16 who attended the baseline assessment starting the second block (6-12 weeks) and 10 still exercising during weeks 12 to 18 (25\% drop-out). However, most of the reasons provided for dropping out of the program such as not being able to find the time due to school and workplace commitments and mental health issues may have not been directly related to the exercise program itself, i.e., its content. 
The drop-out rates in our study were higher compared to those reported with a similar age group by Slaman and colleagues (2015b) which included motivational interviewing and the study by Taylor and colleagues (2013) in which all the sessions were supervised. It is possible that adding strategies such as motivational interviewing and a dedicated supervisor to our study intervention would have helped to retain more participants to exercise program and to the study. However, our exercise program was designed with sustainability in mind and these strategies may be cost-prohibitive in the long-term. Furthermore, in a review on attrition rates in exercise trials in similar age-groups targeting obesity, attrition rates in exercise trials lasting more than 12 weeks were reported to range from $27 \%$ to $55 \%$ (Skelton \& Beech, 2011). A sustainable solution to minimize drop-out and maximize exercise session adherence may be a student mentor system in which a physiotherapy or exercise physiology student exercises with the young person with a disability (Shields et al., 2019).

The delivery of exercise trials for adolescents both with and without disabilities aged 1625 may be especially challenging, with a variety of factors playing a role such as increased autonomy, lack of motivation and the availability of transport (Bloemen et al., 2015) alongside increased demands on time related to education (Tappe et al., 1989). Lack of time due to educational commitments was given as reasons by two participants for not starting or dropping out of the exercise program.

Mental health and fatigue are two other reasons given for drop-out and may also be potential barriers to enrolling or continuing with an exercise program in this group. For example, Jacobson, Löwing and Tedroff (2020) reported that $16 \%$ of the sample of 61 of young adults with $\mathrm{CP}$ were on anti-depressant medication (compared to 6\% in general population of the same age) and $41 \%$ reported problems with fatigue.

For the adolescents who followed the exercise program, adherence to the prescribed number of exercise sessions ( $81 \%$ in Block 1) was similar to that reported for a strengthening trial with adolescents with CP (Ryan et al., 2020). However, the data from the logbooks showed that adherence reduced in Block 2 and the majority of the ten participants who continued with exercise sessions during block 3 (week 13-18) did so only once or twice a week. This suggests that this maybe the preferred exercise frequency for most in this group. From the feedback questionnaire it was also clear that for most, three times a week was perceived as too much of a commitment and thus would not be sustainable long term. Although three weekly exercise sessions have been stated as being the minimum frequency required for improvement in fitness for the general population (American College of Sports Medicine, 2013), Verschuren and colleagues (2016) recommended that for people with CP, especially those more deconditioned, once or twice a week may be sufficient to elicit a training response. For example, the researchers who investigated the impact of RaceRunning involving young people with CP classified as GMFCS level II-IV showed that training for 10 weeks twice a week increased muscle thickness (Hjalmarsson et al., 2020).

The majority of the participants reported that the program structure i.e., the intensity, session duration, progression and variation was just right. However, several participants would have preferred to change the intensity and increase the variety of the exercises which suggests that exercise programs should be flexible and individualized not only with regard to physical ability but also personal preference. Durstine and colleagues (2000) suggested enjoyment is an important element for young adults deciding whether or not to continue with the exercise program on regular basis in the future. The importance of enjoyment of exercise and physical activity for young people with CP has also been highlighted by others (e.g. Sienko, 2019).

Another characteristic related to enjoyment and preference is social interaction which is regarded as an important facilitator for participation in exercise (Sienko, 2019). However, 
while five of the 11 participants preferred to exercise in a group, four preferred to exercise alone and two stating no preference, indicating that this potential facilitator depends on individual preference.

Further, another important aspect of an exercise program for people with $\mathrm{CP}$ and in fact most people with a mobility impairment, is the level of support available either from a student 'mentor' (Shields et al., 2019) or health professional (Rimmer et al., 2004). The support from the physiotherapist and the fitness instructor on duty was valued, as indicated from the feedback questionnaire answers. This should be taken into account when designing/prescribing sustainable exercise programs for adolescents with CP but this also needs to be balanced against the costs this involves.

\section{Feasibility of conducting the trial}

Recruitment rate was low with only 16 of the 431 young people who were sent information on the study (4\%) consenting to take part. This is lower than the recruitment rate reported by Ryan et al. (2020) in which 66 of the 26610 to 19-year-olds consented to participate. Our low recruitment rate could have led to a selection bias. People aged 16-25 may have different priorities, gain more autonomy and may have more demands on their time and in the case of those with $\mathrm{CP}$ also often experience an increase in pain and fatigue occurs often (Jacobson et al., 2020), causing barriers to exercise participation. In addition, the outcome assessments involved with this study may also have been a barrier for adolescents with CP to take part. Many young people with CP have had many medical appointments throughout their childhood and it may be possible that some may feel averse to even more assessments as an adolescent. Studies investigating the efficacy of exercise programs should carefully plan assessments minimizing both the burden and the time spent attending study assessments. For example, assessment burden may be decreased by scheduling study assessments at the time and place of their usual exercise session.

Finally, the contact details used for recruitment were based on the latest gait analysis appointment which may not have been the current address to find the adolescent and thus partially contributing to the low recruitment rate. Reaching young people who have been discharged from pediatric services can be challenging and researchers may want to consider using social media to enhance trial recruitment (Darmawan, Bakker, Brockman, Patten, \& Eder 2020).

The results of the feedback questionnaire demonstrated that all participants perceived some benefit of the program on their physical fitness and increased aerobic fitness was the most often reported benefit $(n=5)$. It is possible that the participants may have expected an increase in fitness by taking part in the exercise program and this expectation could have positively influenced their perceived fitness (Noble, Conditt, Cook, \& Mathis, 2006). It is also possible that for participants who previously had limited experience with aerobic exercise, the perceived increase in fitness could be related to the fact that they became more used to the feeling of exertion. However, even if the perceived improvement in physical fitness does not match an improvement in objectively recorded fitness, there is evidence that perceived fitness is associated with participation in activities of daily living and mood (Plante, Lantis, \& Checa, 1998) and thus may aid future exercise participation.

\section{Strengths and limitations}

The main limitation of this study is the low number of participants recruited to the study. Although 14 participants attended for the assessments at To and T1, this reduced to $\mathrm{n}=11$ at $\mathrm{T} 2$ and $\mathrm{n}=8$ at $\mathrm{T}_{3}$, which is lower than the minimum of 12 per arm suggested for a pilot study (Julious, 2005). Other limitations include the lack of a more extensive follow-up to fully investigate sustainability of the program in the long-term and the fact that taking 
part in the exercise program was free for the participants which may not be the case in all community settings. Further, our feedback questionnaire was specifically constructed for this study and has not been validated. However, we feel that the strength of this study lies in the community setting of the exercise program and the exploration of its potential sustainability. We performed a detailed analysis of the feasibility aspects of both the community exercise program itself and those aspects related to conducting the study. To our knowledge, apart from the study by Shields et al. (2019) which included 19 participants with a range of physical and intellectual disabilities, such an analysis has not been performed for an exercise program including both adolescents with $\mathrm{CP}$.

\section{Conclusions}

The results of this study showed that for the majority of the participants exercising at a local leisure centre was feasible in terms of acceptance and safety. Adherence to the exercise program varied greatly among participants who completed between 5 and 23 weeks of the program. School/workplace commitments $(n=2)$, mental health $(n=1)$ and fatigue $(n=1)$ were reasons provided for dropping out of the exercise program. The findings suggest that an exercise frequency between 1 and 2 times a week was the preferred and therefore probably the most sustainable exercise frequency for most participants. Further, the questionnaire results suggest that personal preference with regard to the exercise content and mode as well as the support from the physiotherapist and fitness instructor on duty are important factors to consider.

\section{Perspectives}

This is one of the first studies providing a detailed report of a range of feasibility aspects with regard to a community-based exercise program for adolescents with $\mathrm{CP}$. We experienced difficulties recruiting participants for this study especially those who had left pediatric services. The findings of this study can be used to inform the design of sustainable exercise options for adolescents with CP.

\footnotetext{
Author affiliations:

1 Centre for Rehabilitation and Special Needs Studies, Faculty of Health Sciences, Universiti Kebangsaan Malaysia, Jalan Raja Muda Abdul Aziz, 50300 Kuala Lumpur, Malaysia

2 Centre for Health, Activity and Rehabilitation Research, Queen Margaret University, Edinburgh, EH21 6UU, UK

3 NHS Lothian, Edinburgh, UK

* Correspondence: asfarina.zanudin@ukm.edu.my; Tel.: +60-392897354
}

Author Contributions: Conceptualization, A.Z, M.V.D.L,K.J, C.S, G.M, T.M.; Methodology, A.Z, M.V.D.L, C.S, T.M.; Formal Analysis, A.Z, M.V.D.L.; Writing-Original Draft Preparation, A.Z.; Writing-Review \& Editing, A.Z, M.V.D.L, K.J, T.M. C.S, G.M.

Funding: This work was supported by the James and Grace Anderson Trust fund, La Fondation Motrice, Ministry of Higher Education of Malaysia and Universiti Kebangsaan Malaysia.

Acknowledgments: We thank all the individuals who participated in this study.

Conflicts of Interest: The authors declare no conflict of interest.

\section{References}

American College of Sports Medicine. (2013). ACSM's resource manual for guidelines for exercise testing and prescription (9th ed.). Philadelphia, PA: Lippincott Williams \& Wilkins

Benner, J.L., Hilberink, S.R., Veenis, T., Stam, H.J., van der Slot, W.M., \& Roebroeck. M.E. (2017). Long-term deterioration of perceived health and functioning in adults with cerebral palsy. Archives of Physical Medicine and Rehabilitation, 98(11), 2196-2205. https://doi.org/10.1016/j.apmr.2017.03.013

Biddle, S. J., Fox, K., \& Boutcher, S. (2003). Physical activity and psychological wellbeing. Abingdon, Oxon: Routledge. 
Blackman, J.A., \& Conaway, M.R. (2014). Adolescents with cerebral palsy: transitioning to adult health care services. Clinical Pediatrics, 53(4), 356-63.

https://doi.org/10.1177/0009922813510203

Bloemen, M. A., Backx, F. J., Takken, T., Wittink, H., Benner, J., Mollema, J., \& de Groot, J. F. (2015). Factors associated with physical activity in children and adolescents with a physical disability: a systematic review. Developmental Medicine \& Child Neurology, 57(2), 137-148. https://doi.org/10.1111/dmcn.12624

Bonnefoy-Mazure, A., De Coulon, G., \& Armand, S. (2020). Self-perceived gait quality in young adults with cerebral palsy. Developmental Medicine \& Child Neurology, 62(7), 868-873. https://doi.org/10.1111/dmcn.14504

Borg G. (1998). Borg's perceived exertion and pain scales. Champaign, IL: Human kinetics.

Bottos, M., Feliciangeli, A., Sciuto, L., Gericke, C., \&Vianello, A. (2001). Functional status of adults with cerebral palsy and implications for treatment of children. Developmental Medicine \& Child Neurology, 43(8), 516-528. https://doi.org/10.1017/s0012162201000950

Bowen, D. J., Kreuter, M., Spring, B., Cofta-Woerpel, L., Linnan, L., Weiner, D., Bakken, S., Kaplan, C. P., Squiers, L., Fabrizio, C., \& Fernandez, M. (2009). How we design feasibility studies. American Journal of Preventive Medicine, 36(5), 452-457. https://doi.org/10.1016/j.amepre.2009.02.002

Cohen, J. (1988). Statistical power analysis for the behavioral sciences. New York, NY: Lawrence Erlbaum Associates

Darmawan, I., Bakker, C., Brockman, T. A., Patten, C. A., \& Eder, M. (2020). The role of social media in enhancing clinical trial recruitment: scoping review. Journal of Medical Internet Research, 22(10), e22810. https://doi.org/10.2196/22810

Diener, E. (1994). Assessing subjective well-being: Progress and opportunities. Social Indicators Research, 31(2), 103-157. https://doi.org/10.1007/bf01207052

Dodd, K. J., Taylor, N. F., \& Graham, H. K. (2003). A randomized clinical trial of strength training in young people with cerebral palsy. Developmental Medicine \& Child Neurology, 45(10), 652-657. https://doi.org/10.1017/s0012162203001221

Durstine, J. L., Painter, P., Franklin, B. A., Morgan, D., Pitetti, K. H., \& Roberts, S. O. (2000). Physical activity for the chronically ill and disabled. Sports Medicine, 3o(3), 207-219. https://doi.org/10.2165/00007256-200030030-00005

El-Kotob, R., \& Giangregorio, L. M. (2018). Pilot and feasibility studies in exercise, physical activity, or rehabilitation research. Pilot and Feasibility Studies, 4, 137. https://doi.org/10.1186/s40814-018-0326-0

Erdfelder, E., Faul, F., \& Buchner, A. (1996). GPOWER: A general power analysis program. Behavior Research Methods, Instruments, \& Computers, 28(1), 1-11.

Espín-Tello, S. M., Dickinson, H. O., Bueno-Lozano, M., Jiménez-Bernadó, M. T., \& Caballero-Navarro, A. L. (2018). Functional capacity and self-esteem of people with cerebral palsy. American Journal of Occupational Therapy, 72(3), 1-8. https://doi.org/10.5014/ajot.2018.025940

Hjalmarsson, E., Fernandez-Gonzalo, R., Lidbeck, C., Palmcrantz, A., Jia, A., Kvist, O., Pontén, E., \& von Walden, F. (2020). RaceRunning training improves stamina and promotes skeletal muscle hypertrophy in young individuals with cerebral palsy. $B M C$ Musculoskeletal Disorders, 21(1), 193. https://doi.org/10.1186/s12891-020-03202-8

Jacobson, D. N., Löwing, K., \& Tedroff, K. (2020). Health-related quality of life, pain, and fatigue in young adults with cerebral palsy. Developmental Medicine \& Child Neurology, 62(3), 372-378. https://doi.org/10.1111/dmcn.14413

Julious, S. A. (2005). Sample size of 12 per group rule of thumb for a pilot study. Pharmaceutical Statistics, 4(4), 287-291. https://doi.org/10.1002/pst.185

Kiapekos, N., Broström, E., Hägglund, G., \& Åstrand, P. (2019). Primary surgery to prevent hip dislocation in children with cerebral palsy in Sweden: a minimum 5-year follow-up by the national surveillance program (CPUP). Acta Orthopaedica, 90(5), 495500.https://doi.org/10.1080/17453674.2019.1627116

Lai, B., Lee, E., Wagatsuma, M., Frey, G., Stanish, H., Jung, T., \& Rimmer, J. H. (2020). Research trends and recommendations for physical activity interventions among 
children and youth with disabilities: A review of reviews. Adapted Physical Activity Quarterly, 37(2), 211-234. https://doi.org/10.1123/apaq.2019-0081

Lauruschkus, K., Westbom, L., Hallström, I., Wagner, P., \& Nordmark, E. (2013). Physical activity in a total population of children and adolescents with cerebral palsy. Research in Developmental Disabilities, 34(1), 157-167.

https://doi.org/10.1016/j.ridd.2012.07.005

Liljenquist, K., O'Neil, M. E., \& Bjornson, K. F. (2018). Utilization of physiotherapy services during transition for young people with cerebral palsy: a call for improved care into adulthood. Physiotherapy, 98(9), 796-803. https://doi.org/10.1093/ptj/pzyo68

Majnemer, A., Shikako-Thomas, K., Lach, L., Shevell, M., Law, M., Schmitz, N., Poulin, C., \& QUALA Group (2014). Rehabilitation service utilization in children and youth with cerebral palsy. Child: Care, Health and Development, 4O(2), 275-282. https://doi.org/10.1111/cch.12026

McMullen, T., \& Resnick, B. (2013). Self-esteem among nursing assistants: reliability and validity of the Rosenberg Self-Esteem Scale. Journal of Nursing Measurement, 21(2), 335-344. https://doi.org/10.1891/1061-3749.21.2.335

Noble, P. C., Conditt, M. A., Cook, K. F., \& Mathis, K. B. (2006). The John Insall Award: Patient expectations affect satisfaction with total knee arthroplasty. Clinical Orthopaedics and Related Research, 452, 35-43. https://doi.org/10.1097/01.blo.0000238825.63648.1e

Opheim, A., McGinley, J., Olsson, E., Stanghelle, J., \& Jahnsen, R. (2013). Walking deterioration and gait analysis in adults with spastic bilateral cerebral palsy. Gait \& Posture, 37(2), 165-171. https://doi.org/10.1016/j.gaitpost.2012.06.032

Palisano, R., Rosenbaum, P., Walter, S., Russell, D., Wood, E., \& Galuppi, B. (1997). Development and reliability of a system to classify gross motor function in children with cerebral palsy. Developmental Medicine \& Child Neurology, 39(4), 214-223. https://doi.org/10.1111/j.1469-8749.1997.tbo7414

Plante, T.G., Lantis, A. \& Checa, G. (1998). The influence of perceived versus aerobic fitness on psychological health and physiological stress responsivity. International Journal of Stress Management 5, 141-156 https://doi.org/10.1023/A:1022936930992

Rimmer, J. H., Riley, B., Wang, E., Rauworth, A., \& Jurkowski, J. (2004). Physical activity participation among persons with disabilities: barriers and facilitators. American Journal of Preventive Medicine, 26(5), 419-425. https://doi.org/10.1016/j.amepre.2004.02.002

Rimmer, J. H., Chen, M. D., \& Hsieh, K. (2011). A conceptual model for identifying, preventing, and managing secondary conditions in people with disabilities. Physical Therapy, 91(12), 1728-1739. https://doi.org/10.2522/ptj.20100410

Russell, D. J., Rosenbaum, P. L., Wright, M., Avery, L. M. (2002). Gross motor function measure (GMFM-66 \& GMFM-88) user's manual. London: Mac Keith Press.

Ryan, J. M., Cassidy, E. E., Noorduyn, S. G., \& O'Connell, N. E. (2017). Exercise interventions for cerebral palsy. Cochrane Database Systematic Review, 6(6). https://doi.org/10.1002/14651858.CD011660.pub2

Ryan, J. M., Lavelle, G., Theis, N., Noorkoiv, M., Kilbride, C., Korff, T., Baltzopoulos, V., Shortland, A., Levin, W., \& Star Trial Team (2020). Progressive resistance training for adolescents with cerebral palsy: the STAR randomized controlled trial. Developmental Medicine \& Child Neurology, 62(11), 1283-1293. https://doi.org/10.1111/dmcn.14601

Seniorou, M., Thompson, N., Harrington, M., Stebbins, J., \& Theologis, T. (2002). Reliability of strength measurements in healthy children and children with cerebral palsy using a digital myometer Gait \& Posture, 16(Suppl 1), 175-6. https://doi.org/10.1016/Sog66-6362(02)00097-8

Shields, N., van den Bos, R., Buhlert-Smith, K., Prendergast, L., Taylor, N. (2019). A community-based exercise program to increase participation in physical activities among youth with disability: a feasibility study. Disability and Rehabilitation, 41(10), 1152-1159. https://doi.org/10.1080/09638288.2017.1422034

Sienko, S. (2019). Understanding the factors that impact the participation in physical activity and recreation in young adults with cerebral palsy (CP). Disability and Health Journal, 12(3), 467-472. https://doi.org/10.1016/j.dhjo.2019.02.008 
Skelton, J.A., \& Beech, B.M. (2011). Attrition in paediatric weight management: a review of the literature and new directions. Obesity Review, 12(5), e273-e281.

https://doi.org/10.1111/j.1467-789x.2010.00803.x

Slaman, J., van den Berg-Emons, H. J. G., van Meeteren, J., Twisk, J., van Markus, F., Stam, H. J., van der Slot, W.M., \& Roebroeck, M. E. (2015a). A lifestyle intervention improves fatigue, mental health and social support among adolescents and young adults with cerebral palsy: Focus on mediating effects. Clinical Rehabilitation, 29(7), 717-727. https://doi.org/10.1177/0269215.5145.55136

Slaman, J., Roebroeck, M., Dallmeijer, A., Twisk, J., Stam, H., van den Berg-Emons, R., \& Learn 2 Move Research Group. (2015b). Can a lifestyle intervention program improve physical behaviour among adolescents and young adults with spastic cerebral palsy? A randomized controlled trial. Developmental Medicine \& Child Neurology, 57(2), 159166. https://doi.org/10.1111/dmcn.12602

Tappe, M. K., Duda, J. L., \& Ehrnwald, P. M. (1989). Perceived barriers to exercise among adolescents. The Journal of School Health, 59(4), 153-155. https://doi.org/10.1111/j.1746-1561.1989.tb04689.x

Taylor, N.F., Dodd, K.J., Baker, R.J., Willoughby, K., Thomason, P., \& Graham, H.K. (2013). Progressive resistance training and mobility-related function in young people with cerebral palsy: a randomized controlled trial. Developmental Medicine \& Child Neurology, 55(9), 806-12. https://doi.org/10.1111/dmen.12190

Tickle-Degnen, L. (2013). Nuts and bolts of conducting feasibility studies. American Journal of Occupational Therapy, 67(2), 171-176. http://doi.org/10.5014/ajot.2013.006270

Verschuren, O., Takken, T., Ketelaar, M., Gorter, J.W., \& Helders, P.J. (2006). Reliability and validity of data for 2 newly developed shuttle run tests in children with cerebral palsy. Physical Therapy, 86(8), 1107-17. https://doi.org/10.1093/ptj/86.8.1107

Verschuren, O., Ketelaar, M., Gorter, J. W., Helders, P. J., Uiterwaal, C. S., \& Takken, T. (2007). Exercise training program in children and adolescents with cerebral palsy: a randomized controlled trial. Archives of Pediatrics \& Adolescent Medicine, 161(11), 1075-1081. https://doi.org/10.1001/archpedi.161.4.356

Verschuren, O., Peterson, M. D., Balemans, A. C., \& Hurvitz, E. A. (2016). Exercise and physical activity recommendations for people with cerebral palsy. Developmental Medicine \& Child Neurology, 58(8), 798-808. https://doi.org/10.1111/dmcn.13053

(C) 2021 by the authors. Submitted for possible open access publication under the terms and conditions of the Creative Commons Attribution (CC BY) license (http://creativecommons.org/licenses/by/4.o/). 